\title{
Granulomatosis eosinofílica con Poliangeitis: presentación inusual de una enfermedad rara en la edad pediátrica
}

\author{
[Eosinophilic granulomatosis with polyangiitis: unusual presentation of a rare disease in pediatric age]
}

Dra. Ana Karina Coronado', Dra Kelineth Canto'², Dr. Humberto Serrud ${ }^{3}$, Dra. Dorothee Stichweh ${ }^{4}$

${ }^{1}$ Médico Residente Pediatría II año, Hospital Materno Infantil José Domingo de Obaldía, ${ }^{2}$ Médico Especialista en Gastroenterología pediátrica y nutrición, Hospital Materno Infantil José Domingo de Obaldía, ${ }^{3}$ Médico Especialista en Neumología pediátrica, Hospital Materno Infantil José Domingo de Obaldía, ${ }^{4}$ Pediatra Reumatóloga. Hospital del Niño José Renán Esquivel, Panamá.

Correspondencia: Dra. Ana Karina Coronado MD.

Correo electrónico: karina coronado@hotmail.com

Recibido: 6 de enero de 2021

Publicado: 1 de abril de 2021

Cita: Coronado, AK, (2020), Granulomatosis eosinofílica con Poliangeitis: presentación inusual de una enfermedad rara en la edad pediátrica, DOI: 10.37980/im.journal.rspp.20201708

Palabras clave: granulomatosis eosinofílica con poliangeitis, síndrome ChurgStrauss, vasculitis, ANCA.

Key words: Eosinophilic granulomatosis with polyangiitis, Churg-Strauss syndrome, vasculitis, ANCA.

Reproducción: Artículo de acceso libre para uso personal e individual. Sujeto a derechos de reproducción para otros usos.

Conflictos de interés: Los autores declaran no tener conflictos de interés. Los autores declaran que han seguido los protocolos de su centro de trabajo sobre la publicación de datos de pacientes. Se obtuvo el consentimiento informado por escrito del paciente para la publicación de este reporte del caso y las imágenes que lo acompañan.

Financiamiento: El autor no declara fuentes externas de financiamiento asociados a este trabajo.

\section{Resumen}

La granulomatosis eosinofílica con poliangitis (GEPA), es un trastorno poco frecuente en la edad pediátrica, representando menos de un $2 \%$ de las vasculitis en pediatría. Su etiología es desconocida y de difícil diagnóstico debido a la variabilidad en su cuadro clínico. Los pacientes presentan como rasgo característico antecedentes de asma, rinitis alérgica y eosinofilia en sangre periférica. A nivel microscópico es una vasculitis necrosante que afecta a vasos de pequeño a mediano calibre, presencia de granulomas y eosinofilia extravascular. ${ }^{1,2}$ La GEPA es una vasculitis asociada a la presencia de anticuerpos anticitoplasma de neutrófilo (ANCA), su positividad en niños sólo se encuentran en menos del $40 \%$ de los casos. Presentamos el caso de una escolar de 8 años con cuadros respiratorios recurrentes asociados a eosinofilia superior al $10 \%$, manifestaciones cutáneas importantes, esofagitis eosinofílica y polineuropatía, finalmente diagnosticado con GEPA-ANCA-PR3 (ANCA específico para proteinasa 3).

\section{Abstract}

Eosinophilic granulomatosis with polyangiitis (EGPA) is a rare disorder in pediatric age, accounting for less than $2 \%$ of vasculitis in pediatrics. Its etiology is unknown and difficult to diagnose due to the variability in its clinical picture. Patients have a history of asthma, allergic rhinitis and eosinophilia in peripheral blood as a characteristic feature. Microscopically, necrotizing vasculitis that affects small to medium-caliber vessels, the presence of granulomas and extravascular eosinophilia., ${ }^{1,2}$ GEPA is a vasculitis associated with the presence of anti-neutrophil cytoplasmic antibodies (ANCA), its positivity in children is only found in less than $40 \%$ of cases. We present the case of an 8-year-old schoolgirl with recurrent respiratory symptoms associated with eosinophilia greater than $10 \%$, important skin manifestations, eosinophilic esophagitis and polyneuropathy, finally diagnosed with GEPA-ANCA-PR3 (specific ANCA for proteinase 3 ).

Introducción

La granulomatosis eosinofílica con poliangitis también conocida con el nombre síndrome de Churg-Strauss (SCS) fue descrita histopatológicamente por primera vez, en 1951, por Jacob Churg y Lotte Strauss. ${ }^{3}$

Se asocia a la presencia de anticuerpos anti-citoplasma de neutrófilo (ANCA), que afecta pulmón, nervios periféricos, piel y, de manera menos frecuente, corazón, riñones y tubo digestivo. ${ }^{4}$ Asociado con la presencia de granulomas eosinofílicos extravasculares, eosinofilia periférica y asma. Antes de 1999, solo se habían notificado diez casos de SCS en niños, el paciente más joven reportado tenía 2 años. ${ }^{5}$
Presentamos el caso de una paciente de 8 años, la cual fue hospitalizada con cuadro asmático, bajo peso y manifestaciones cutáneas crónicas de difícil manejo asociados con eosinofilia periférica y tisular, que luego de la realización de estudios concluimos el diagnóstico de Granulomatosis eosinofílica con Poliangeitis. Por la forma de presentación y evolución clínica consideramos de interés científico el reporte de este caso clínico.

\section{Caso clínico}

Femenina de 8 años y 7 meses, con antecedente de cuadros respiratorios de vías respiratorias inferiores recurrentes que 
requirieron hospitalización a los 11, 22 y 28 meses de edad, cursando con desaturaciones, requerimiento de corticoesteroides sistémicos e inhalados, asociado en la mayoría de las hospitalizaciones a manifestaciones cutáneas, bajo peso y eosinofilia mayor del $10 \%$ sin evidencia de parásitos en heces. Padres consanguíneos, sin antecedentes familiares de alergia.

Ingresa con historia de 10 días de evolución de cuadro caracterizado por rinorrea hialina asociado a 3 días de tos seca, no cianosante, no emetizante y el día previo a su ingreso con datos de dificultad respiratoria progresiva. Con historia de lesiones cutáneas múltiples y crónicas de aspecto heterogéneo (Pápulas abundantes en cara; áreas de hipopigmentación cutánea en tronco anterior y posterior. Uñas con acropaquias y onicolisis. Miembros inferiores con lesiones purpúricas palpables que no desaparecen a la digitopresión, ascendentes. Nódulos ulcerados en tercio distal de piernas y tobillos).

Madre refiere lesiones en piel tratadas como impétigo desde los 3 años de vida. Pérdida de aproximadamente 5 libras de peso e hiporexia de un mes de evolución. No asociado a dolor ni limitación para sus actividades diarias.

Al Examen Físico: Paciente con bajo peso (peso: $18.4 \mathrm{Kg}$, taIla $116 \mathrm{~cm}$. IMC 13.7, Percentil 7 para la edad), con hallazgos dermatológicos múltiples, granuloma en mejilla derecha, lesiones eccematosas y áreas de hipopigmentación cutánea (Figura 1). A la auscultación pulmonar con rudeza respiratoria, crépitos bilaterales.

Biometría hemática reporta leucocitosis de 29,300 a expensas de eosinófilos (53.1\%), elevación de reactantes de fase aguda Velocidad de eritrosedimentación: $120 \mathrm{~mm} / \mathrm{h}$ y elevación de transaminasas ALT $171 \mathrm{U} / \mathrm{L}$, AST $62 \mathrm{U} / \mathrm{L}$. IgE: 4,230 Ul/mL.

Por datos de neumopatía crónica (figura 2), se sospecha Fibrosis quística (bronquiectasias, sinusitis crónica, cultivo de lavado broncoalveolar (LAB) positivo por Pseudomonas aeruginosa, bajo peso severo). Se le realizaron determinaciones de cloro en sudor seriadas: Wescor $64 \mathrm{mmol} / \mathrm{L}$, \#3 Clorochek dentro de rango normal ( $19 \mathrm{mmol} / \mathrm{L} ; 33 \mathrm{mmol} / \mathrm{L} ; 38 \mathrm{mmol} / \mathrm{L}$ ). Prueba de reacción en cadena de la polimerasa e hibridación para el gen CFTR (del acrónimo en inglés de Cystic fibrosis transmembrane conductance regulator ) para 24 mutaciones negativa. Elastasa pancreática normal. Con lo anterior se descarta sospecha inicial de fibrosis quística e insuficiencia pancreática.

A nivel gastrointestinal con antecedente de alergia alimentaria y bajo peso severo. Se realiza endoscopia alta con hallazgo por histopatología de esofagitis eosinofílica (figura 3). Se inicia dieta de eliminación de 6 alimentos: leche, trigo, soya, huevo, nueces, pescados/mariscos e inhibidor de bomba de
Figura. 1. A. Pápulas abundantes en cara. B: Áreas de hipopigmentación cutánea en tronco anterior y posterior. C: Acropaquias y onicolisis. D: Lesiones purpúrica palpable que no desaparecen a la digitopresión, ascendentes. E: Nódulos ulcerados en tercio distal de piernas y tobillos.
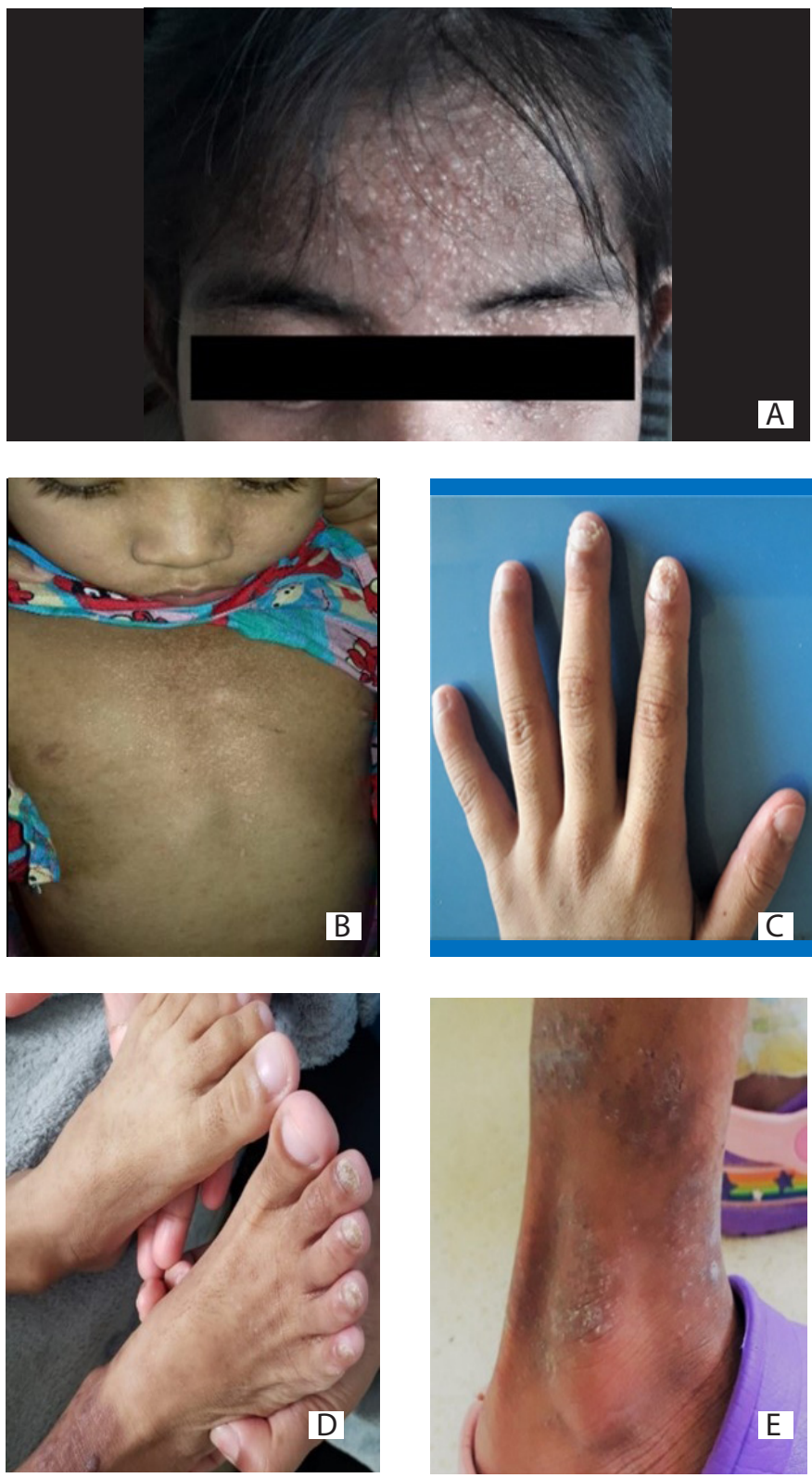

protones a $1 \mathrm{mg} / \mathrm{kg} /$ dosis BID al día. Por un periodo de tiempo de 12 semanas.

Por datos de neumopatía crónica con bronquiectasias se solicita alfa 1 antitripsina sérica la cual resulta dentro de rango normal $(289 \mathrm{mg} / \mathrm{dL})$

Por el importante compromiso sistémico (tabla \#1), infiltración a nivel de tracto respiratorio, gastrointestinal y dérmico de eosinófilos, púrpura palpable, marcada eosinofilia periférica, y el compromiso neurológico, ANCA-C positivo (inmu- 
Figura 2: Patrón retículo nodular bilateral, cisuritis con bronquiectasias asociadas

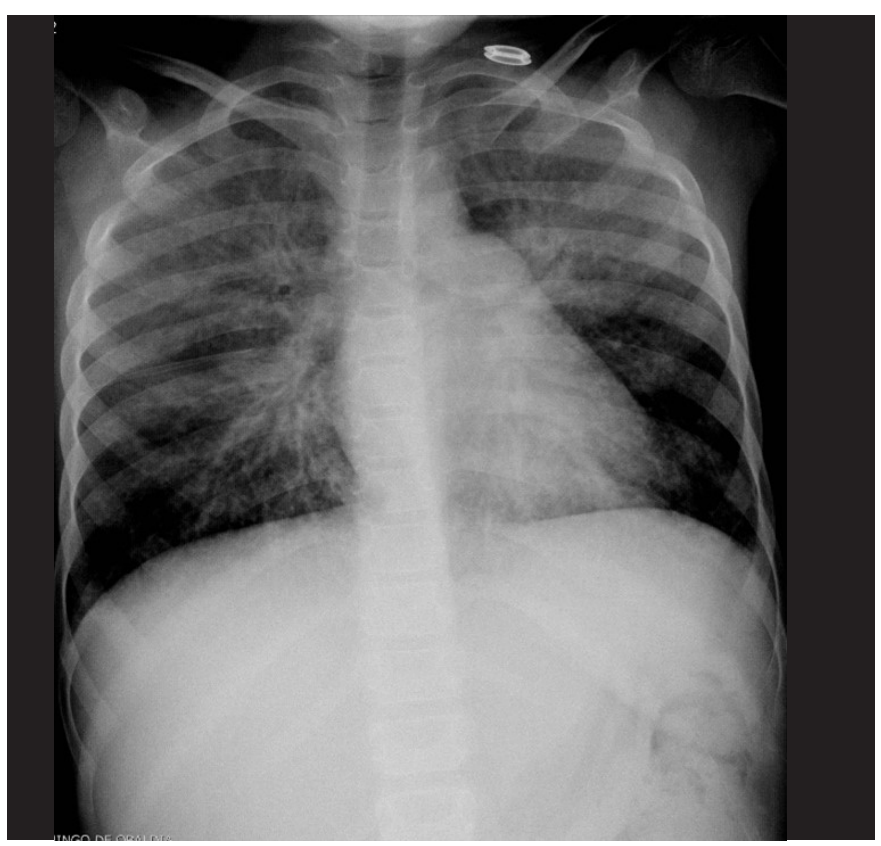

Figura 3: A: Surcos esofágicos longitudinales. Hallazgo de esofagitis Eosinofílica. B: control endoscópico luego de 4 semanas.
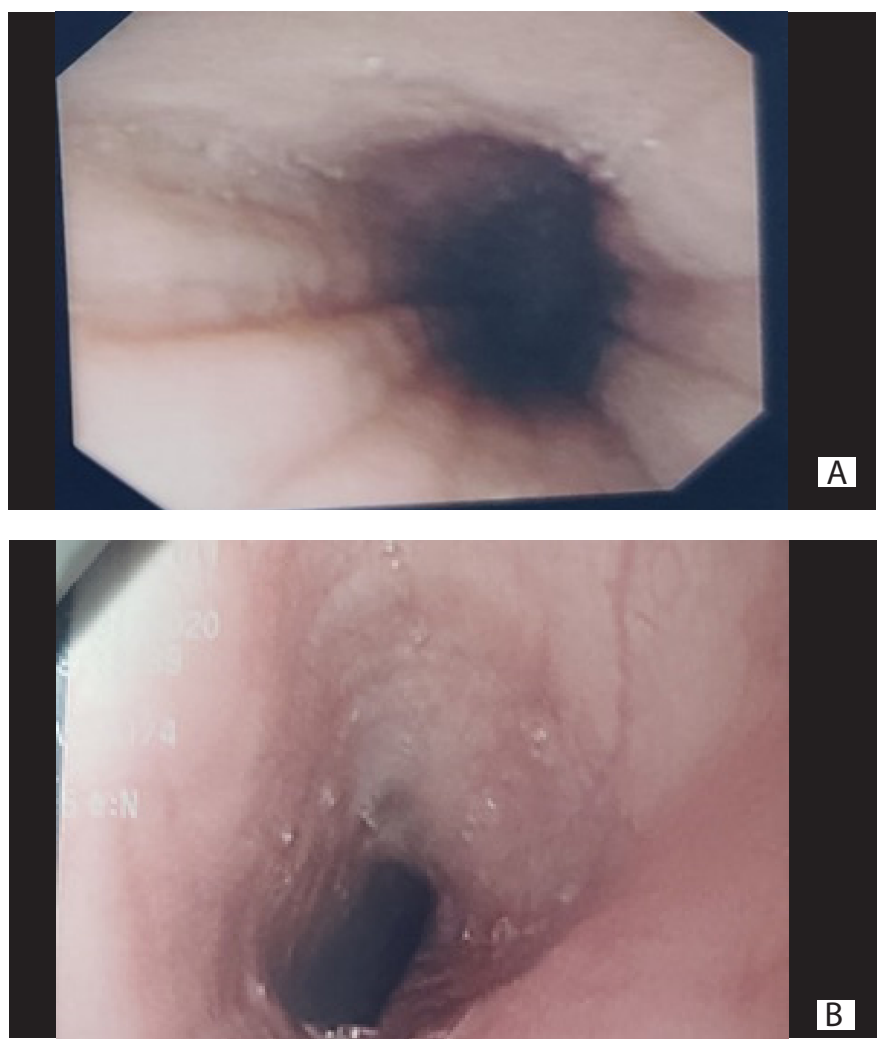

nofluorescencia), integramos el diagnóstico de una Granulomatosis eosinofílica con poliangeítis. Se consulta a servicio de reumatología quienes están de acuerdo con el diagnóstico y se inician pulsos intravenosos de metilprednisolona 30 $\mathrm{mg} / \mathrm{kg} /$ dosis por 3 días e inmunosupresión con ciclofosfa-
Tabla 1. Manifestaciones sistémicas y estudios de gabinete

\begin{tabular}{|c|c|}
\hline Neurológico & $\begin{array}{l}\text { Velocidad de conducción nerviosa: } \\
\text { polineuropatía mixta desmielinizante } \\
\text { sensitiva-motora de miembros inferiores. } \\
\text { Predomina el compromiso desmielinizante } \\
\text { de ambos nervios perineales. }\end{array}$ \\
\hline & $\begin{array}{l}\text { Sinusitis crónica, Asma, espirometría } \\
\text { demostró una obstrucción reversible de la } \\
\text { vía aérea. }\end{array}$ \\
\hline Respiratorio & $\begin{array}{l}\text { Radiografía de tórax: Infiltrados pulmonares } \\
\text { migratorios, CAT Tórax: Bronquiectasias } \\
\text { cilíndricas, infiltrados de patrón retículo } \\
\text { nodular, adenopatías mediastínicas. Proceso } \\
\text { granulomatoso. }\end{array}$ \\
\hline Dermatológico & $\begin{array}{l}\text { Biopsia de piel con infiltrado perivascular y } \\
\text { perifolicular de células mononucleares en } \\
\text { dermis superficial y profunda, eosinófilos } \\
\text { perianexiales. }\end{array}$ \\
\hline Gastrointestinal & $\begin{array}{l}\text { Alergias alimentarias } \\
\text { Endoscopia: Esofagitis crónica } 24-25 \\
\text { eosinófilos por campo de alto poder, } \\
\text { gastritis crónica, duodenitis crónica. } \\
\text { Elastasa pancreática: } 504 \text { normal, } \\
\text { Anti-transglutaminasa IgG, IgA negativa. } \\
\text { Anti-gliadina Negativa } \\
\text { Alfa } 1 \text { anti-tripsina normal }\end{array}$ \\
\hline Renal & Relación proteína/Creatinina al azar: 0.35 \\
\hline Inmunológico & $\begin{array}{l}\text { Fiebre alta intermitente } \\
\text { ANTI-DNA: negativa } \\
\text { ANA: } 3.702 \text {, positivo } \\
\text { ANCA C: positivo } \\
\text { ANCA P: negativo } \\
\text { Factor reumatoide } 8.6 \\
\text { IgG elevada, IgM normal } \\
\text { MI-2 Positivo } \\
\text { C3 y C4 normales }\end{array}$ \\
\hline Hematológico- Infeccioso & $\begin{array}{l}\text { VES } 120 \mathrm{~mm} / \mathrm{H} \text {, leucocitosis a expensas } \\
\text { eosinófilos 53\%, trombocitosis reactiva. }\end{array}$ \\
\hline
\end{tabular}

Fuente: Expediente Clínico Hospital José Domingo de Obaldía

mida con aplicación cada 4 semanas, a dosis de $0.65 \mathrm{~g} / \mathrm{m}^{2} /$ dosis. Con buena respuesta luego de 4 semanas de iniciar el tratamiento, mejoría de función pulmonar, no dependiente de oxígeno, mejoría de esofagitis (Figura 3B) y descenso de cifras de eosinófilos.

\section{Discusión}

La granulomatosis eosinofílica con poliangeítis (GEPA) es un vasculitis rara con una incidencia anual de 0.24 por cada 100,000 niños. ${ }^{6,7}$ Según la actualización en la nomenclatura de las vasculitis en la Conferencia de Consenso Internacional de Chapel Hill , GEPA se define como un proceso inflamatorio granulomatoso necrotizante rico en eosinófilos que a menudo involucra el sistema del tracto respiratorio, con vasculitis necrotizante predominantemente afectando vasos pequeños a medianos, asociados con asma y eosinofilia. ${ }^{2}$ 
Eleftheriou y colaboradores, observaron un retraso significativo en el diagnóstico, hasta 7,3 años en una serie de casos. ${ }^{1}$ Ya que GEPA es posiblemente una de las formas más raras de vasculitis que afecta a los niños, el bajo índice de sospecha casi seguramente contribuye a retraso diagnóstico significativo. Actualmente no existen criterios de diagnóstico validados para GECPA, y en a usencia de evidencia clínica o histológica de vasculitis, generalmente es difícil diferenciar GECPA de otros trastornos eosinofílicos sistémicos que afectan la población pediátrica. ${ }^{1}$

Clásicamente, GECPA se caracteriza por un pródromo inicial de rinitis asmática y síntomas alérgicos, seguidos de un período hipereosinofilia en sangre periférica y acumulación de eosinófilos extravasculares, y una etapa final de vasculitis sistémica. ${ }^{6}$

El órgano más afectado es el pulmón, dentro de la afectación extrapulmonar observadas con frecuencia se describe la enfermedad cutánea, y gastrointestinales, manifestaciones cardíacas a veces con desenlace fatal. ${ }^{7}$ Esta paciente fue tratada de forma crónica como dermatitis atópica y alergias alimentarias.

La distinción de la GECPA en comparación con los otros tipos de vasculitis, es la asociación con eosinófilos en sangre periférica y asma acompañado de granulomas extravasculares y vasculitis necrosante. ${ }^{8.9}$

Durante la evolución natural de la enfermedad se ha observado, incluso antes de la aparición de vasculitis y/o asma, que las manifestaciones de GECPA pueden simular otras enfermedades por ejemplo, síndrome hipereosinofílico, para lo cual es recomendable la valoración de los diagnósticos diferenciales de hipereosinofilia. En este caso la paciente presentaba a nivel pulmonar bronquiectasias, por lo que se valoró la asociación de estas con el síndrome de hiperlgE (SHE), sin embargo, presentaba ausencia de las características fenotípicas, score NIH en 23. (Tabla 2) Distinguir entre GECPA y el SHE puede ser todo un reto, particularmente en las etapas tempranas de la enfermedad, debido a que ambos síndromes comparten características clínicas y serológicas; además, es mucho más difícil distinguirlos en pacientes con anticuerpos anticitoplasma de neutrófilos (ANCAs) negativos y ausencia histológica de vasculitis. En este caso la positivad del ANCA asociado a las manifestaciones ya descritas nos orientó más hacia la GECPA. ${ }^{10,11,12}$

Los criterios diagnósticos definidos por la American College of Rheumoatology (ACR) en $1990^{13}$ (Tabla \#3). Se ha demostrado que los ANCA se encuentran con menos frecuencia en GEPA en comparación con otras vasculitis asociadas a ANCA. ${ }^{1}$ El patrón principal de fluorescencia es el perinuclear con anticuerpos contra MPO (pANCA- ANCA específico para proteína Mieloperoxidasa) en un $40 \%$; sin embargo, también
Tabla 2. Características paraclínicas de la GEPA y el Síndrome Hipereosinofílico

\begin{tabular}{|c|c|c|}
\hline Características & GEPA & SHE \\
\hline Infiltrados pulmonares & ++ & ++ \\
\hline Granulomas & + & - \\
\hline Compromiso pericárdico & + & + \\
\hline $\begin{array}{l}\text { Fracción de eyección } \\
\text { disminuida }\end{array}$ & ++ & ++ \\
\hline Fibrosis miocárdica & - & ++ \\
\hline Miocarditis & ++ & + \\
\hline Arritmias & ++ & + \\
\hline Mono/polineuropatía & +++ & +++ \\
\hline Gastroenteritis eosinofílica & ++ & ++ \\
\hline IgE total aumentada & +++ & +++ \\
\hline \multicolumn{3}{|l|}{ Lavado bronquio alveolar } \\
\hline Alveolitis hemorrágica & + & - \\
\hline Alveolitis eosinofílica & ++ & + \\
\hline \multicolumn{3}{|l|}{ Biopsia de piel } \\
\hline Eosinofilia & +++ & +++ \\
\hline Vasculitis & ++ & + \\
\hline Granuloma & + & - \\
\hline Asma & +++ & + \\
\hline Sinusitis & +++ & + \\
\hline Manifestaciones cutáneas & ++ & +++ \\
\hline
\end{tabular}

Fuente: López-Piedrahita E, et al, (2014) 39:174-184. GEPA: granulomatosis eosinofilica con Poliangeitis; SHE: Síndrome de hiperlgE

Tabla 3. Criterios de Clasificación Granulomatosis eosinofílica con poliangeitis (Churg-Strauss)

\section{Al menos cuatro de los seis siguientes:}

\section{Asma}

\section{Eosinofilia periférica $>10 \%$}

3. Mono- o polineuropatía, atribuible a vasculitis sistémica

4. Infiltrados pulmonares migratorios

5. Anormalidades de los senos paranasales

6. Eosinofilia extravascular: biopsia incluyendo arterias,arteriolas o vénulas mostrando acúmulos de eosinófilos en áreas extravasculares.

Fuente ${ }^{13}$ Masi AT, Hunder GG, Lie JT, Michel BA, Bloch DA, Arend WP, et al. The American College of Rheumatology 1990 criteria for the classifcation of Churg-Strauss syndrome (allergic granulomatosis and angiitis). Arthritis Rheum. 1990;33:1094-100.

se pueden encontrar anticuerpos contra PR3 (CANCA- ANCA específico para proteína Proteinasa 3) en una minoría de pacientes.

La presencia de ANCA positivos se correlaciona con afectación renal, con síntomas constitucionales y con otras manifestaciones sistémicas y de órganos específicos, como la mononeuritis, púrpura y hemorragia pulmonar'. En contraste, la ausencia de ANCA se correlaciona con mayor frecuencia a manifestaciones pulmonares (con la excepción de la hemorragia alveolar) y cardíacas. En este caso no encontramos 
alteración cardiaca, ni nefritis. Esta observación sugiere que el SCS puede agrupar al menos dos entidades clínicas o fenotipos distintas.

Aunque el papel de los ANCA en la patogenia de estas vasculitis no está completamente dilucidado, muchos estudios han confirmado que constituyen un marcador indispensable para la categorización de estas vasculitis de mediano y pequeño vaso, las cuales pueden exhibir rasgos clínicos y microscópicos indistinguibles. ${ }^{14,15,16,17}$

Con respecto a las manifestaciones clínicas se describe la evolución de la enfermedad a lo largo de tres fases clínicas sucesivas: un primer estadio prodrómico en el que predominan las manifestaciones alérgicas (rinitis, asma, pólipos nasales, alergia a fármacos -antibióticos fundamentalmente-,alergia alimentaria, al polvo o al polen), un segundo estadio que cursa con hipereosinofilia sanguínea e infiltrados tisulares de eosinófilos (neumonía eosinofilia de Löffler, infiltración miocárdica y gastroenteritis eosinofílica) y un tercer estadio de vasculitis sistémica con afectación de diferentes órganos (sobre todo piel, sistema nervioso periférico y riñones).

Las manifestaciones en pacientes pediátricos se describen son variables y dependiente del fenotipo ANCA. Nuestra paciente curso con manifestaciones pulmonares (asma, bronquiectasias), dérmicas, e infiltración gastrointestinal, esofagitis eosinofílicas y alergias alimentarias.

Los infiltrados pulmonares son muy característicos y se observan en el $40 \%-50 \%$ de los casos. Son parcheados o difusos, migratorios y recidivantes (síndrome de Loffler), y de localización predominantemente periférica. El asma se presenta casi en el $100 \%$ de los casos; suele ser grave, con frecuentes estatus asmáticos, corticodependiente e incluso corticorresistente. ${ }^{4,17}$

Uno de los hallazgos en este caso a nivel pulmonar fue presencia de eosinófilos en el lavado broncoalveolar y adenopatías mediastínicas. Ambas descritas como otras manifestaciones pulmonares que podemos encontrar en estos pacientes En este caso nos pudo realizar biopsia pulmonar por el riesgo anestésico. Las bronquiectasias con sobre infección pulmonar crónica también pueden preceder a la fase vasculítica en varios años. El asma suele permanecer como sintomatología residual tras la remisión de la vasculitis con el tratamiento. Demostrado por espirometría luego de 4 semanas de inicio de tratamiento con inmunosupresor y pulsos de corticoides cada 4 semanas.

Las manifestaciones cutáneas constituyen una manifestación temprana común en la niñez, presentándose en 50-70\% de los casos como lesiones que pueden ser variables: lesiones maculopapulares difusas, púrpura palpable, nódulos eritematosos o petequias, las cuales pueden ser pruriginosas.
Algunas de las manifestaciones gastrointestinales descritas en la literatura están relacionadas con Infiltración eosinofílica de la mucosa gastrointestinal, que causa ulceraciones isquémicas en paredes gástricas, intestinales o colorrectales o pseudo-oclusión del intestino delgado ${ }^{18,19}$ y quizás el esófago. Eleftherio y col, en una serie de casos de 13 pacientes pediátricos reportaron 3 de 13 casos con esofagitis eosinofílica, y todos con gastroduodenitis y colitis. ${ }^{1}$

La mononeuritis múltiple, se presenta en el 70\%-80\% de los casos. Afecta sobre todo a los nervios peroneo común, tibial posterior, sural, poplíteo interno, cubital, mediano y radial. Suele ser de tipo sensitivo-motor. Puede llegar a ser grave e invalidante y dejar sintomatología residual permanente. La polineuropatía simétrica o asimétrica y la neuropatía sensorial son también frecuentes. ${ }^{20,21}$

En este caso la paciente no presentó datos de nefritis, en el primer abordaje no fue posible la realización de la biopsia renal por su condición. Sin embargo, se realizan seguimiento de proteína/creatina al azar y más por su positividad de ANCA. Se describe que el $75 \%$ de los casos con nefropatía son ANCA positivos frente al $25 \%$ de los pacientes que no presentan esta complicación. La mortalidad a los 5 años en el primer grupo es del $12 \%$ y en el segundo del $2,7 \%{ }^{1}$

Otras anormalidades frecuentes encontradas en niños son la alteración a nivel de senos paranasales (65\%), afectación cardiaca (38.6\%), La gran mayoría de los pacientes presenta eosinofilia y leucocitos en rangos de leucemia, y niveles elevados de lgE en más de la mitad de los casos.

\section{Tratamiento}

El tratamiento de la vasculitis asociada a ANCA incluye el inicio temprano de inmunosupresores. Nuestra paciente comenzó con ciclofosfamida oral y metilprednisolona en dosis altas (30 mg/kg), donde tuvo una respuesta notable en las primeras semanas.

\section{Conclusiones}

Los hallazgos clínicos descritos en este caso nos orientaron al diagnóstico de Granulomatosis eosinofílica, en este caso ANCAc positivo.

Debido a su baja prevalencia representa un reto diagnóstico que puede retrasar su identificación y tratamiento. Este reporte busca enfatizar la importancia de considerar la GEPA como un diagnóstico diferencial en el asma de difícil control en niños, especialmente cuando ésta se asocia a hipereosinofilia y afección multiorgánica que pudiera sugerir vasculitis, especialmente en piel. El reconocimiento temprano de la enfermedad y el manejo multidisciplinario es importante, ya que el diagnóstico tardío puede conducir a una afectación sistémica grave y puede llevar a resultados fatales. 
El éxito del tratamiento va a depender de la adherencia al tratamiento y la fase de la enfermedad en la cual fue diagnosticada.

\section{Contribuciones de los autores}

Todos los autores contribuyeron a escribir y editar el manuscrito. Todos los autores leyeron y aprobaron el manuscrito final.

\section{Agradecimiento}

Colaboración del Servicio de Neumología (Dr. Gherson Cukier, Dr. Evens Chong, Dr. Humberto Serrud), Gastroenterología (Dra. Kira Alvarado), Nefrología (Dra. Magdanis Renovales) y Nutrición del Hospital José Domingo de Obaldía.

Dra. Dorothee Stichweh, Reumatología, Hospital del Niño Dr. José Renán Esquivel.

\section{Referencias}

1. Eleftheriou D, Gale H, Pilkington c, et al. Eosinophilic granulomatosis with polyangiitis in childhood: retrospective experience from a tertiary referral centre in the UK. Rheumatology 2016;55:1263_1272

2. Bielsa, I. Update of Systemic Vasculitides Nomenclature. International Chapel Hill Consensus Conference, 2012. Actas Dermosifiliogr. 2015;106(8):605---608.

3. Castellano J et al. Sindrome de Churg Strauss.http://www. svreumatologia.com/wp-content/ uploads/2008/04/Cap-15Sindrome-de-ChurgStrauss.pdf). pp 277-288

4. Azamar Jácome AA, García Domínguez M, Rodríguez M, Méndoza Hernández DA , Escamilla C. Churg-Strauss: presentación de un caso, Pediátrica,. 2015;24(2):Mayo-agosto: 68-72.

5. Sharma SR, Habung $H$, Hussain M. Churg-Strauss syndrome in a pediatric patient presenting with recurrent hemorrhagic stroke and mitral regurgitation due to a prolapsed mitral valve. Neurol India. 2016;64(4):827-830. doi:10.4103/00283886.185374

6. Sablé-Fourtassou R, Cohen P, Mahr A, et al.; French Vasculitis Study Group. Antineutrophil cytoplasmic antibodies and the Churg-Strauss syndrome. Ann Intern Med 2005;143(9):632638.

7. Zwerina J, Eger G, Englbrecht M, Manger B, Schett G. ChurgStrauss syndrome in childhood: a systematic literature review and clinical comparison with adult patients. Semin Arthritis Rheum 2009;39(2):108-15. doi: 10.1016/j.semarthrit.2008.05.004.

8. Klion AD, Bochner BS, Gleich GJ, et al.; The Hypereosinophilic Syndromes Working Group. Approaches to the treatment of hypereosinophilic syndromes: a workshop summary report. J Allergy Clin Immunol 2006;117(6):1292-1302.

9. Tomac N, Yuksek M, Kunak B, Ertan U, Igde M. ChurgStrauss syndrome: a patient report in infancy. Clin Pediatr (Philadelphia) 2003;42(4):367-370.

10. US National Institutes of Health. http://www.niaid.nih.gov/LabsAndResources/labs/aboutlabs/lcid/stat3base/Documents/ scoringsystem.pdf Accessed january 10,2014.

11. Tagle MT, Melys A, Castillo A, et al. Síndrome Hiper lgE: a propósito de tres casos clínicos. Rev Chil Pediatr 2014; 85 (3): 328-336

12. López-Piedrahíta E, Ramírez-Giraldo RH, Velásquez-Franco $\mathrm{CJ}$, et al. Hypereosinophilic syndrome and Churg-Strauss syndrome. Spectrum of the same disease? New concepts. Acta Med Colomb 2014; 39: 174-184.

13. Masi AT, Hunder GG, Lie JT, Michel BA, Bloch DA, Arend WP, et al. The American College of Rheumatology 1990 criteria for the classification of Churg-Strauss syndrome (allergic granulomatosis and angiitis). Arthritis Rheum. 1990;33:1094-100.

14. Lacruz Pérez L. Granulomatosis de Wegener, arteritis de Takayasu, síndrome de Churg-Strauss, vasculitis primaria del sistema nervioso central y otras vasculitis. Protoc diagn ter pediatr. 2014;1:141-9

15. O'Neil KM. Progress in pediatric vasculitis. Curr Opin Rheumatol. 2009;21:538-46.

16. Rodríguez-Armendáriz R, Hernández-Saldaña R, Hinojos Gallardo LC, Ramos-Martinez, E, Soto-Ramos M. Granulomatosis eosinofílica con poliangitis: reporte de un caso y revisión de la literatura . Neumol Cir Torax, 2017:76(1): 36-43.

17. Jennette JC, Falk RJ, Bacon PA et al. 2012 revised international Chapel Hill Consensus Conference nomenclature of vasculitides. Arthritis Rheum 2013;65:1-11.

18. Imaeda H, Yamaoka M, Ohgo H, Yoneno K, Kobayashi T, Nogochi $\mathrm{T}$, et al . Eosinophil infiltration in the upper gastrointestinal tract of patients with bronchial asthma. Allergology International 2016;65: 6-10.

19. Bochner BS, Book W, Busse WW, Butterfield J, Furuta JT, Gleich $\mathrm{G}$, et al. Workshop Report from the NIH Taskforce on the Research Needs of Eosinophil-Associated Diseases (TREAD). J Allergy Clin Immunol. 2012 September ; 130(3): 587-596. doi:10.1016/j.jaci.2012.07.024

20. Hattori $N$, Ichimura $M$, Nagamatsu $M$, Li $M$, Yamamoto $K$, Kumazawa K, et al. Clinicopathological features of ChurgStrauss syndrome- associated neuropathy. Brain 1999; 122: 427-439.

21. Cattaneo L, Chierici E, Pavone L, Grasselli C, Manganelli P, Buzio $C$, et al. Peripheral neuropathy in Wegener's granulomatosis, Churg-Strauss syndrome and microscopic polyangiitis. J Neurol Neurosurg Psychiatry. 2007; 78: 1119-23. 